\title{
Defect Reduction with the Use of Seven Quality Control Tools for Productivity Improvement at an Automobile Company
}

\author{
Imdad Ali Memon \\ Department of Mechanical Engineering, \\ Quaid-e-Awam University of \\ Engineering, Science \& Technology, \\ Nawabshah, Pakistan \\ engineerimdad@yahoo.com
}

\section{Muhammad Kashif Abbasi}

Department of Mechanical Engineering, Quaid-e-Awam University of

Engineering, Science \& Technology,

Nawabshah, Pakistan

muhammadkashif@quest.edu.pk

\author{
Qadir Bakhsh Jamali \\ Department of Mechanical Engineering, \\ Quaid-e-Awam University of \\ Engineering, Science \& Technology, \\ Nawabshah, Pakistan \\ qjamali@quest.edu.pk
}

Nisar Ahmed Jamali

Department of Mechanical Engineering, Quaid-e-Awam University of

Engineering, Science \& Technology,

Nawabshah, Pakistan

nisarjamali101@gmail.com

\author{
Abdul Sattar Jamali \\ Department of Mechanical Engineering, \\ Quaid-e-Awam University of \\ Engineering, Science \& Technology, \\ Nawabshah, Pakistan \\ jamali_sattar@quest.edu.pk
}

\section{Zahid Hussain Jamali \\ Department of Mechanical Engineering, Quaid-e-Awam University of \\ Engineering, Science \& Technology, \\ Nawabshah, Pakistan \\ zahidhussain0804@gmail.com}

\begin{abstract}
The goal of zero defects is pursued by many manufacturing and service companies. In this regard, statistical tools are being used for defect reduction leading to productivity improvement. In this work, seven traditional QC tools (flow chart, check sheet, histogram, Pareto chart, cause, and effect diagram, scatter diagram and control chart) have been developed and implemented in an automobile company to assess and improve the defect reduction level in the assembly line. Chassis and trim lined were selected for data collection to assess and improve the defect level for productivity improvement. It was found from the results that after the successful implementation of the QC tools, the defect level reduced by $90 \%$ (from 132 to 13 defects) at the chassis line. Similarly, the defect level was reduced by $80 \%$ (from 157 to 28 defects) at the trim line. The automobile company implemented only a few of the seven QC tools in their assembly line. It is suggested that the company may need to manage a mechanism for the implementation of all seven QC tools in every section of the company.
\end{abstract}

Keywords-vehicle inspection department (VID); chassis line; tim Line; 7 QC tools

\section{INTRODUCTION}

Statistical process control (SPC) plays a major role in the reduction of variations in any manufacturing and service enterprise. The problem solving tools used in SPC, called the "management seven" [1], are traditional management tools, namely check sheets, histogram, Pareto chart, cause and effect diagram, scatter diagram and control chart. These tools are very popular and are commonly called the 7 QC tools. Their applications for quality improvement are found in almost all manufacturing and service organizations. Many researchers have done successful implementations of these tools in their work. They were implemented in Jordan industry in [2]. The major causes of non-conformities and the root causes of quality problems were specified, and possible remedies were proposed. Continuous improvement techniques are currently used in multiple USA industries. The 7 old tools were compared with new 7 tools in [3]. SPC tools such as cause and effect diagram and control charts were implemented in automotive industry. The study in [4] dealt with defects in shocker seals of an automotive industry. The percentage of rejection reduced from $9.1 \%$ to $5 \%$ after the implementation of SPC. The results in [5] showed that the improvement in production processes saved materials and money. The inspection process was made automated and offline SPC was converted into online SPC in [6]. QC tools were used in manufacturing taper shank drills in taper shank drill industry. Check sheet, Pareto diagram, histogram, cause and effect diagram, control chart, run chart and scatter diagram were implemented for productivity improvement in [7]. Highlighted research articles and case studies on the implementation of SPC tools in manufacturing industry are reviewed in [8]. A framework for quality improvement was developed by the authors in [9] using some tools like Pareto chart and fish bone diagram of critical problems. In [10], authors achieved better control in solving the problems of dimensional variations in 3-cylinder metric block casting using Pareto analysis, cause and effect diagram, brain storming, why-why analysis. They suggested remedies which result in quality improvement [10]. The role of the $7 \mathrm{QC}$ tools is obvious even in the increase in customer demand looking for better product quality [11]. Some significant improvements were also observed after SPC tools implementation in process potential capability $(\mathrm{Cp})$, process actual capability $(\mathrm{Cpk})$ and in defective parts per millions (DPM) [12]. 


\section{MATERIALS AND METHODS}

The initial activity was to assess the assembly line of an automobile company through frequent visits for the conformation of the defect level in the vehicle assembly line. Two inspection points, chassis line and trim line were identified for data collection by the Vehicle Inspection Department (VID). Chassis line included wheels section, whole frame engine section with fuel wiring and battery wiring. Trim line included a combined portion of shade, seats and dashboard. The frequency of defects was observed at both lines.

\section{A. Flow Chart (QC tool-1)}

The chassis and trim lines of VID were monitored for data collection. Eight types of defects (hand brake wire does not drag, wire harness air booster LH side does not insert, brake oil pipe touches with chassis LH side, clutch oil pipe is not in alignment, fuel pipe touches fuel tank, engine hood damage found, exhaust pipe air wire bkt channel is not settled, compressor pipe is rusted and galvanizing process is not done) were found in chassis line. It was decided by looking the severity of defects that only two defects, namely engine hood damage (EHD) and compressor pipe rusted (CPR) were studied. Similarly, four types of defects were found in trim line and only two, door improper sealed (DIS) and footstep assembly stud impression (FASI) were taken for analysis based on the severity level of their occurrences.

\section{B. Check Sheets (QC Tool-2)}

After identification of the inspection points for data collection, check sheets were developed to collect or mark the defective data for further analysis. Check sheets are the most basic tool out of the seven. Check sheets are forms especially prepared to enable data to be collected simply by checking marks. Check inspectors used these sheets during checking or inspecting e.g. checking the occurrences of defects. The check sheets can be used for both numerical data and attributed data. In this research work, check sheets were designed and used for attributed data e.g. the number of different types of defects found on the chassis and trim lines. Data were collected through check sheets for four months, from November 2015, to February 2016 for both lines.

\section{Histograms (QC Tool-3)}

Histograms were developed based on the data collected through check sheets to display the variation and capability of the process. The frequency of individual defects using histograms for the four months of data collection for chassis and trim Lines was developed through Excel as shown in Figure 1. The frequency of defects observed during November and December was high because the 7 QC tools were not implemented properly. After the application of the 7 QC tools a considerable reduction in defects was observed in January and February. The same pattern in defects reduction was observed in trim line defects as shown in Figure 2.

\section{Pareto Diagrams (QC Tool-4)}

Pareto diagrams represent quality problems and their associate cost in order of their significance. A bar graph identifies the defects shown in descending order of magnitude of occurrences. It differs from histogram in the sense of mentioning the cumulative frequency of defects on its secondary axis and in the trend line showing the cumulative percentage of defects. High frequency of defects occurring can be prioritized using this chart. The Pareto diagrams of defects for chassis and trim lines are shown in Figures 3 and 4 respectively.

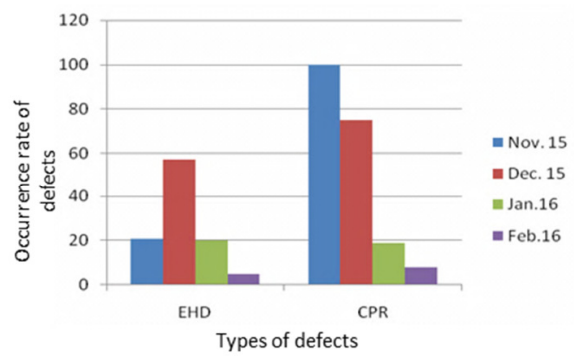

Fig. 1. Histograms for chassis line decfects

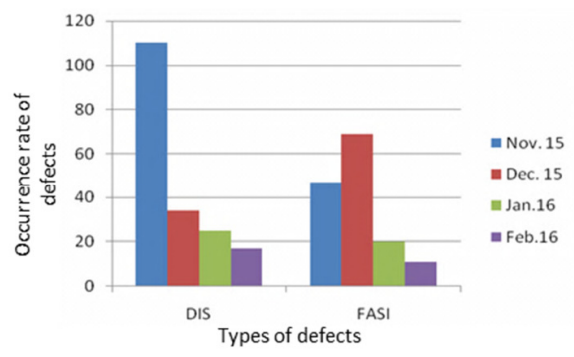

Fig. 2. Histograms for trim line defects

(a)
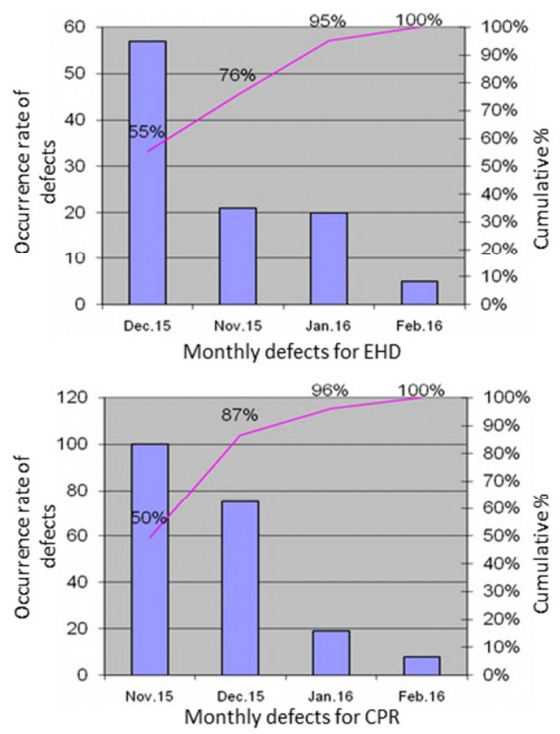

Fig. 3. Pareto chart for chasssis line defects: (a) EHD, (b) CPR

The Pareto chart for EHD represents that $55 \%$ of defects occurred during December, 2015, while $76 \%$ occurred in November and December. The CPR defect percentage in the November was $50 \%$. The Pareto chart for DIS shows that $59 \%$ occurred in November, while the accumulative percentage of November and December was $77 \%$. FASI defect's percentage 
in December was $47 \%$ and the accumulative percentage for November and December was $79 \%$.

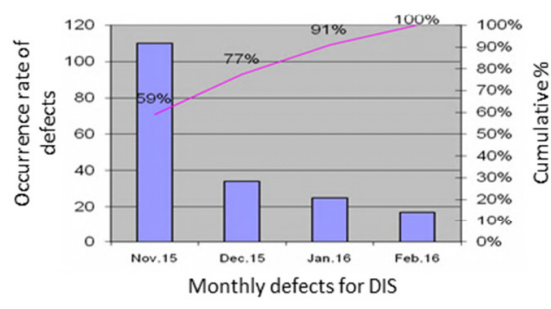

(b)

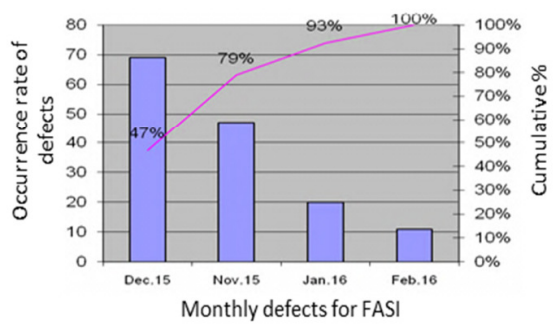

Fig. 4. Pareto chart for trim line defects: (a) DIS, (b) FASI

\section{E. Cause and Effect Diagram (QC Tool-5)}

It is used for analyzing the causes of problems which occur in products, processes or systems. The reasons of defects at chassis and trim lines can be easily identified by this tool. The initial data from the check sheets for November and December, 2015 found that the defect level was very high. Therefore, cause and effect diagram was used to find the defects' root causes. Data were also collected through check sheets for January and February, 2016 to check any improvement in defect level. The cause and effect diagram for both lines for the selected defects is shown in Figures 5 and 6 respectively.

(a)

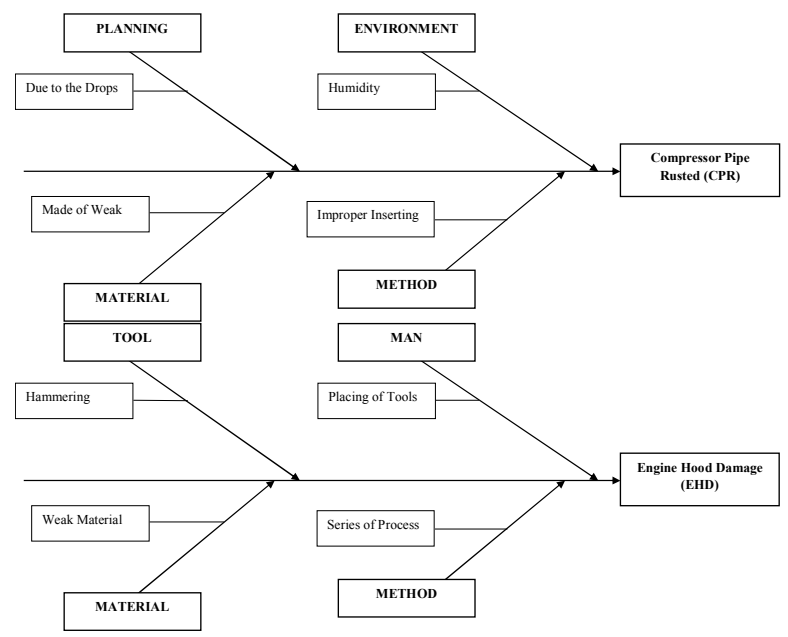

Fig. 5. Cause and effect diagram for chassis line defects (a) EHD, (b) CPR

\section{F. Scatter Diagram (QC Tool-6)}

Its purpose is to study and evaluate the inter relationship between two characteristics. The effect of one characteristic on the other can be observed by the use of a scatter diagram. The number of defects with respect to time was observed for chassis line and trim line as shown in Figure 7 and 8 respectively. We see that defects had negative correlation with time.

(a)

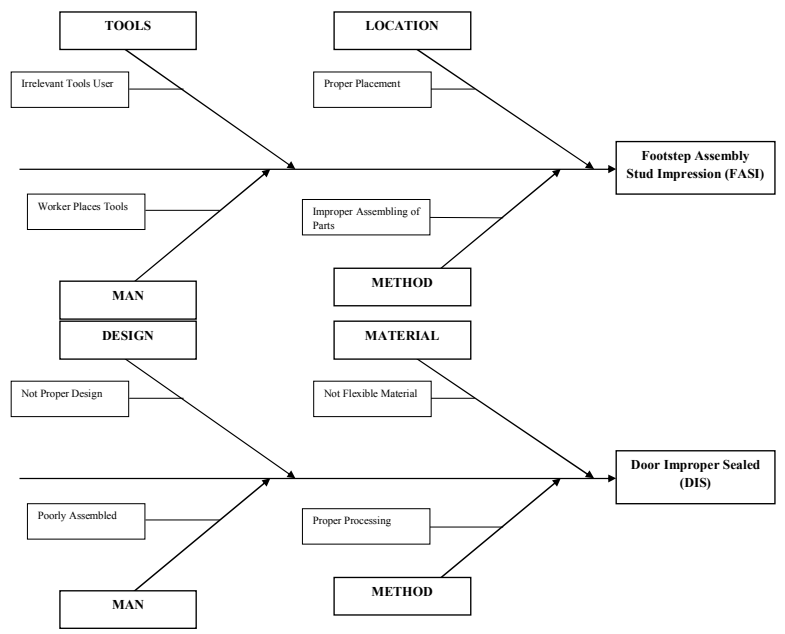

Fig. 6. Cause and effect diagram for trim line defects: (a) DIS, (b) FASI

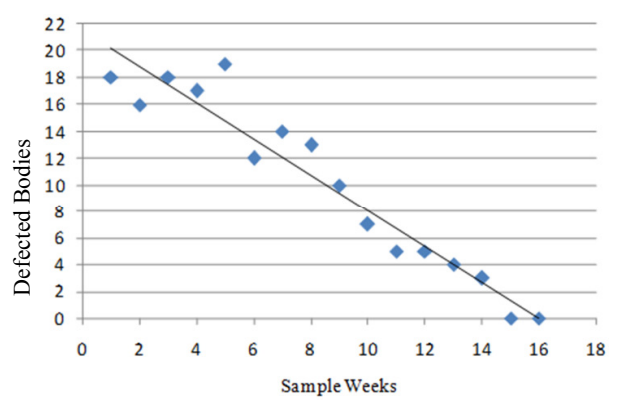

Fig. 7. Scatter diagram for chassis line defects

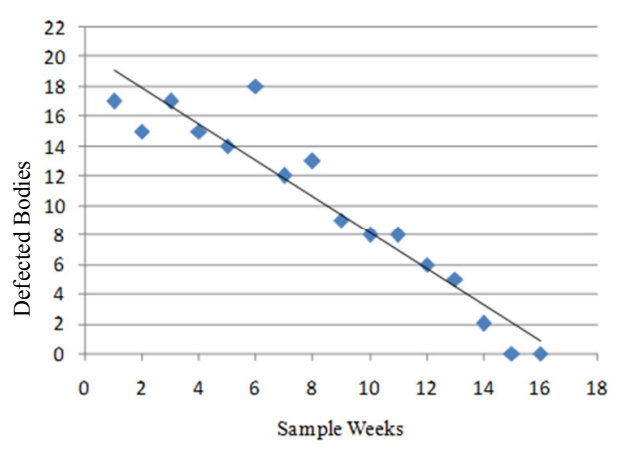

Fig. 8. Scatter diagram for trim line defects

\section{G. P-Chart (QC Tool-7)}

$\mathrm{P}$-Chart is a data analysis technique for determining if a measurement process has gone out of statistical control. It is sensitive to changes in the number of defective items in the measurement process. The "P" stands for the mean number of successes of a binomial distribution. The P-control charts for chassis and trim lines are shown in Figures 9 and 10 respectively. The biggest reduction in defect level was observed in week 7 in chassis line and week 9 in trim line. 


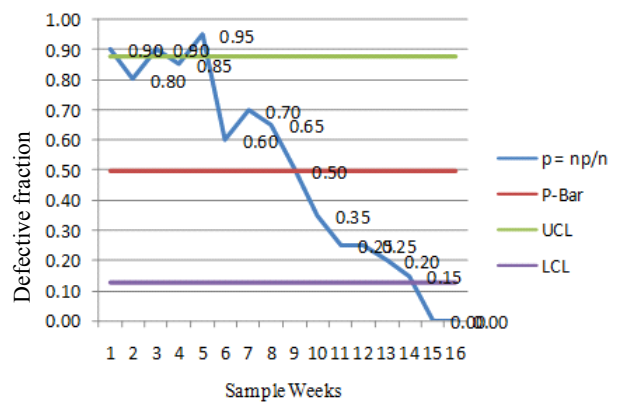

Fig. 9. Control chart for chassis line

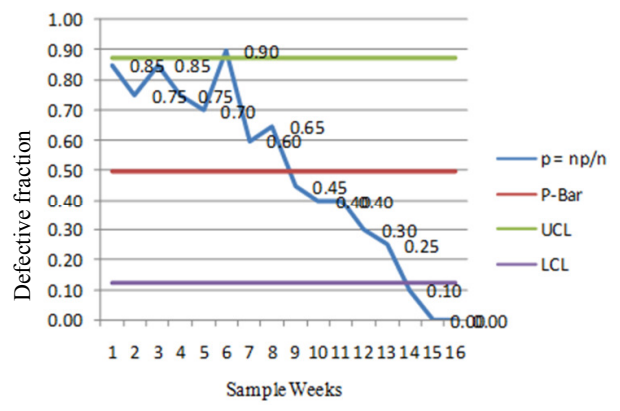

Fig. 10. Control chart for trim line

\section{DEFECT REDUCTION AFTER APPLICATION}

A considerable improvement has been observed after the application of the 7 QC tools in both lines. The defects before and after the application of the 7 QC tools in chassis and trim lines are shown in Figures 11 and 12 respectively.

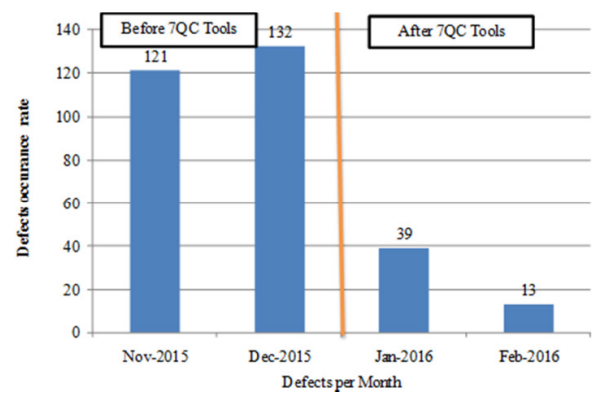

Fig. 11. Reduction in defects in chassis line

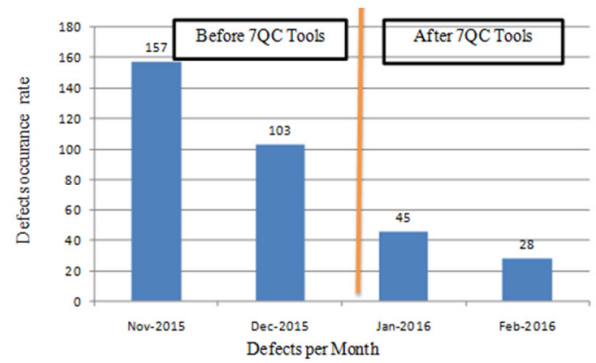

Fig. 12. Reduction of defects in trim line

\section{CONCLUSION}

This research studied the reduction of defects in an assembly line of a VID department of an automobile company. It was observed that the highest frequency of defects in chassis line (EHD and CPR) was 132 defects in December of 2015 (before the application of the 7QC tools) and the lowest defect number (13) was found in February of 2016 (after the application of the 7QC tools). The overall improvement in the reduction of the defects for chassis line was $90 \%$. Regarding the trim line, there were 157 defects in November, 2015 and 28 in February, 2016. The overall improvement in the reduction of defects for the trim line was $82 \%$.

\section{ACKNOWLEDGMENT}

Authors would like to thank the automobile company for giving access at their assembly lines and data, and the YU, KSA and QUEST Nawabshah, Pakistan for the facilities for data analysis. Some data of the company are kept private in accordance with our confidentiality agreement.

\section{REFERENCES}

[1] D. C. Montogmery, Introduction to Statistical Quality Control, John Wiely and Sons, Inc., 1997

[2] R. H. Fouad, A. Mukattah, "Statistical Process Control Tools: A practical guide for Jordian Industrial Organizations", Jordian Journal of Mechanical and Industrial Engineering, Vol. 4, No. 6, pp. 693-700, 2010

3] J. V. Kovach, E. A Cadney, C. C. Elrod, "The Use of Continuous improvement techniques. A survey-based study of current practices", International Journal of Engineering, Science and Technology, Vol. 3, No. 7, pp. 89-100, 2011

[4] D. R. Prajapati, "Implementation of SPC techniques in Automotive Industry: A case study", International Journal of Emerging Technology and Advanced Engineering, Vol. 2, No. 3, pp. 227-241, 2012

[5] M. Aichouni, "On the case of the basic quality tools for the improvement of the construction industry: A case study of a mixed concrete production process", International Journal of Civil and Environmental Engineering, Vol. 12, No. 5, pp. 28-34, 2012

[6] T. V. U. Kiran Kumar, "SPC tools in Automobile component to analyze inspection process", International Journal of Advanced Research in Electrical, Electronics and Instrumentation Engineering, Vol. 2, No. 1, pp. 624-630, 2013

[7] P. J. Patel, S. C. Shah, S. Makwana, "Application of Quality Control Tools in Taper Shank Drills Manufacturing Industry: A case study", International Journal of Engineering Research and Applications, Vol. 4, No. 2, pp. 129-134, 2014

[8] P. S. Parmar, V. A. Desphande, "Implementation of SPC techniques in industry: A review", Journal of Emerging Technologies and Innovative Research, Vol. 1, No. 6, pp. 583-587, 2014

[9] A. Hussain, Q. W. Ahmed, I. Haq, "Improving Productivity and Quality in SMEs of Pakistan", Technical Journal, University of Engineering and Technology, Taxila, Pakistan, Vol. 20, No. 2, pp. 103-114, 2015

[10] A. B. Vante, G. R. Naik, "Quality Improvement for dimensional variations in sand and casting using Quality Control tools", International Journal of Innovative Research in Science, Engineering and Technology, Vol. 4, No. 8, pp. 6917-6926, 2015

[11] D. G. Pendokhare, T. Quazi, P. S. Kulkarni, "Redesign and Manufacturing by using DMADV Method", International Journal of Research in Engineering and Technology, Vol. 4, No. 2, pp. 144-149, 2015

[12] N. Afzaal, A. Aftab, S. Khan, M. Najamuddin, "To analyze the use of Statistical Tools for Cost effectiveness and Quality of products", IOSR Journal of Humanties and Social Science, Vol. 20, No. 1, pp. 47-57, 2015 